\title{
Políticas y Desempeño del Sector Lechero Argentino entre 2003 y 2011
}

Policies and Performance of the Argentine Dairy Sector between 2003 and 2011

\section{Carlos María Alasino \\ Licenciado en Economía (UNC) y Magister en Economía (Universidad de Sao Paulo). Profesor de Economía, Universidad Nacional de Quilmes y Universidad Abierta Interamericana (Facultad de Ciencias Empresariales) carlosalasino@yahoo.com.ar}

\section{Horacio Miguel Arana (h)}

Lic. en Economía Agropecuaria (UB) y Magister en Dirección de Empresas (Universidad Austral). Profesor Titular de Principios de Economía y de Economía Política, Universidad Abierta Interamericana (Facultad de Ciencias Empresariales)

horacio.arana@UAI.edu.ar
Fecha de recepción 08.01 .14

Fecha de aceptación 31.3.14

\section{Resumen}

Los ajustes e intervenciones del Estado en el sector lácteo argentino han tenido en los últimos años diferentes signos, con sentidos y direcciones contradictorios. Durante la década de 1980 se apeló a la Comisión de Concertación de Políticas Lecheras y al Fondo de Promoción a la Actividad Lechera. La desregulación de los años noventa desarticuló ambos mecanismos y en este siglo se asistió nuevamente a una política sectorial de mayor intervención. El trabajo se concentra en este último período describiendo en primer lugar las medidas de política instrumentadas distinguiendo entre aquellas que apuntan al descalce de precios internos e internacionales y las que intentan corregir los nuevos problemas que aparecen. A continuación se evalúan los resultados obtenidos en materia de precios, producción, consumo y exportaciones. Una última sección resume las principales conclusiones. Palabras clave: lechería argentina - política lechera - producción de leche - evolución del sector lechero - consumo de leche.

\footnotetext{
Abstract

Adjustments and state interventions in the Argentine dairy sector have had in recent years different signs, sometimes contradictory meanings and directions as well. In the eighties there was an appeal to both the
} 
Consultation Commission on Dairy Policy and the Fund for the Promotion of the Dairy Sector. Deregulation in the nineties dismantled both mechanisms: yet afterwards a sectorial policy was again implemented which involved greater state intervention. The present work focuses on this latter period, first describing the policy measures aimed to disconnect domestic prices from international prices and those that try to fix the new problems that appear. The results obtained in terms of prices, production, consumption and exports are evaluated. A final section summarizes the main conclusions.

Key words: Argentina's dairy - dairy policy - milk production - evolution of the dairy sector - consumption of dairy products.

\section{Introducción}

La historia del sector lechero en la Argentina de las últimas décadas muestra una marcada tendencia a considerarlo envuelto en un juego de suma cero donde los intereses de la producción aparecen como contrapuestos a la industria y ambos a los consumidores, suponiendo que las ganancias de unos surgen de pérdidas de otros. Asimismo, es casi un lugar común en los tiempos actuales destacar el elevado potencial argentino para la producción láctea, tanto por sus características climáticas cuanto por su fácil acceso a materias primas a precios muy competitivos. ${ }^{1}$

En los últimos treinta años se han instrumentado diversas políticas sectoriales tendientes a concretar este potencial. En los años ochenta se apeló por ejemplo a la Comisión de Concertación de Políticas Lecheras (COCOPOLE) que, con frecuencia mensual, reunía a las asociaciones de productores y a la industria láctea para la discusión del precio al productor, y en caso de no haber acuerdo laudaba el Presidente de la Nación; la ley 23.359 instrumentó también el Fondo de Promoción a la Actividad Lechera (FOPAL), mediante el cual se trataba de disponer de los excedentes exportables con independencia del precio internacional. Gorenstein et al ( 1988) adjudican a la instrumentación de este Fondo el incremento de la producción de leche registrado en 1985 y 1986. La desregulación de los años noventa desarticuló luego ambos mecanismos y en los primeros años de este siglo se asistió nuevamente a una política sectorial con una mayor intervención del Estado, en línea tal vez con las características estructurales mundiales que hacen del sector lácteo a uno de los más regulados en el mundo. Es precisamente 
este último período el que se pretende analizar. En lo que respecta a las regulaciones hubo algunos cambios de reglas de juego en los últimos años a instancias de los acuerdos de la ronda Uruguay del GATT, aunque tales cambios fueron limitados a una acotada reducción del uso de instrumentos distorsivos del comercio, y se ha afirmado que el sector lácteo continúa siendo uno de los más protegidos y subsidiados por parte de muchos países o bloques regionales; las ayudas internas a los productores estimulando la oferta de leche más allá de las posibilidades de la demanda interna, los subsidios a las exportaciones para deshacerse de la producción excedente y las barreras arancelarias y no arancelarias destinadas a proteger las lecherías domésticas han impactado a su vez en los mercados internacionales perjudicando a los países con producción competitiva (Programa de Inserción Agrícola, 2010).

Tanto el gobierno como algunos autores (Nogueira, 2011) destacan el carácter de bienes salario con demanda inelástica que exhiben la leche y algunos derivados, con un mercado de la materia prima de tipo oligopsónico, altamente concentrado, y una oferta mucho mas atomizada. De la misma opinión son Bisang et al (2007;2008), ya que mencionan que la industria muestra un alto grado de concentración en donde 15 empresas reciben el $60 \%$ de la producción, mientras que el sector primario se encuentra atomizado, lo que determina diferencia importantes de poder de negociación entre los actores de la trama láctea. ${ }^{2}$ Nogueira señala asimismo que en los años ochenta el complejo lácteo estuvo orientado básicamente al mercado interno, siendo la trama exportadora de desarrollo más reciente a partir de los años noventa, con Brasil, Australia y en alguna medida Argentina como los países con mayor expansión de la producción. Gorenstenin et al (1988) han enfatizado también el carácter "mercado internista" del sector lácteo argentino en los años ochenta, al igual que Bisang et al (2008). Estos últimos sostienen que la orientación tradicional del sector hacia el mercado interno hizo que las exportaciones tuvieran un comportamiento anticíclico en relación con la demanda local, lo que generó el concepto de "saldo o excedente exportable". Esto fue cambiando a partir de mediados de la década de 1990 con la apertura comercial, la desregulación y la ampliación del mercado (principalmente MERCOSUR). Las modificaciones estructurales de esa década tuvieron como resultado mayor producción y productividad, modernización tecnológica, inversiones en plantas y equipos, aumentos de escala y nuevos mercados.

Los sectores ligados a la producción láctea iniciaron a partir de 2004 un trabajo destinado a diseñar un plan estratégico con horizonte 2020. El Sector Público por su parte desarrolló el Plan Estratégico Agroalimentario y Agroindustrial Participativo y Federal 2006-2020.

El Plan para la Cadena Láctea (Cadena Láctea Argentina 2008) destaca que en 2008 existían 11.168 tambos, ${ }^{3}$ que entregaban su producción a 848 plantas (ubicadas 322 en Córdoba, 276 en Buenos Aires, 162 en Santa Fe, 54 en Entre Ríos y 10 en otras provincias), 9 de las cuales concentraban el 55\%. Los objetivos planteados en el documento 
incluyen alcanzar una producción de 18.000 millones de litros de leche cruda por año, ubicar a la Argentina entre los 4 principales exportadores mundiales y lograr una mayor diversificación y valor agregado.

El presente trabajo se estructura de la siguiente manera. Se describen en primer lugar las medidas de política instrumentadas distinguiendo entre aquellas que apuntan a descalzar los precios internos de los internacionales -acuerdos de precios, precios de referencia y ROE (Registro de Operaciones de Exportación) y aquellas que intentan corregir los nuevos problemas que aparecen a medida que se interviene en los mercados (aportes no reembolsables y compensaciones a productores lecheros e industria e intervención en precios de insumos). A continuación se evalúan los resultados obtenidos en materia de precios, producción, consumo y exportaciones. Una última sección resume las principales conclusiones.

Se espera mostrar que, si bien la situación del sector mejoró significativamente en el período analizado, las políticas instrumentadas no tuvieron una visión integral de largo plazo y no permitieron aprovechar en plenitud la euforia mundial que experimentaron los commodities, permaneciendo sin resolver la contradicción entre un creciente consumo interno de un producto imprescindible para la población y la consolidación de un papel protagónico del país en el mercado lácteo mundial. De todas maneras, se tiene en cuenta lo señalado por Quintana y Reca (2010) en el sentido que los diversos mecanismos de intervención, la incertidumbre que ello conlleva, la crisis en los mercados internacionales y la eventual retracción de la demanda interna no habrían afectado negativamente la producción de leche en la Argentina, no obstante que otros sectores de los agronegocios crecieron significativamente más que la lechería; detrás de esto ubicarían un cambio de modelo de los productores líderes quienes habrían usado más intensivamente insumos como maíz y harina de soja y forrajes sujetos a derechos de exportación que les permiten pagar precios inferiores a los internacionales con el consiguiente menor costo asociado.

\section{Primeras intervenciones del siglo}

Una rápida caracterización del sector lácteo en estos años debe destacar una tendencia declinante de los precios internacionales desde 1997, una reducción del consumo a partir de 2000 fruto de la caída en el nivel de ingreso nacional, merma de la producción y de las exportaciones, problemas de pago del sector industrial con créditos nominados en dólares, caída de los precios al productor en torno de 1999/2000 y una mayor atracción del cultivo de la soja a partir de la devaluación, una actividad que requiere menos inversión y por ende es menos riesgosa que la producción tambera ${ }^{4}$. 
La primera intervención destacable sobre el sector lácteo que se produce en el nuevo siglo ocurre en marzo de 2002 (Secretaría de la Competencia, la Desregulación y la Defensa del Consumidor, 2002). Buscando proteger a los consumidores se fijan precios de referencia para la comercialización de leche cruda y se convoca a una Mesa de Concertación Láctea formada por productores, industriales y representantes de las provincias para que, en un lapso de 60 días se expida sobre: identificación de precios representativos por cuenca lechera, ${ }^{5}$ identificación estructural de márgenes y plazos de pago de comercialización de la cadena; puesta en marcha de un sistema de control de la producción y comercialización de la producción a través de la Oficina Nacional de Control Comercial Alimentario (ONCCA) y la AFIP (Agencia Federal de Ingresos $\mathrm{P}$ \{ublicos); creación de un sistema de identificación de la oferta y la demanda en orden a la promoción de exportaciones; desarrollo de warrants a través de fideicomiso; determinación de mecanismos de fijación de precios y plazos de pago con la participación de la producción primaria y la industria y evaluación de precios de venta al consumidor. Con el fin de atenuar el deterioro de los ingresos fiscales y la creciente demanda de asistencia, el mismo mes se regulan en forma transitoria los derechos de exportación adicionales a los vigentes, los cuales de fijan en 10\% o 5\% dependiendo de la Posición Arancelaria (MEI, Ministerio de Economía e Industria 2002).

En el mismo año se aprueba el "Programa Nacional de Política Lechera"(SAGPyA, Res.320/2002) con el objetivo de crear un ámbito jerarquizado de gestión del sector lácteo debido a su importancia como generador de inversión, empleo y desarrollo tecnológico, y promover la integración de la cadena láctea. De esta manera se define un amplio espectro de áreas de competencia y se crea la Mesa Nacional de Política Lechera $^{6}$ y el Comité Federal de Lechería. ${ }^{7}$

\section{Intervención mediante Derechos, Reintegros y el Programa de Estabilización de Precios de 2007}

En los primeros años posteriores a la devaluación de 2002 se produjo una recuperación importante de la producción y de las exportaciones lácteas, al amparo de mejores precios iternacionales que acrecentaron la competitividad del sector. El consumo interno sin embargo no subió significativamente en una primera instancia y los precios internos tampoco lo hicieron en forma notable. A poco de andar, sin embargo, estos comenzaron a moverse con mayor dinamismo no sólo en el sector lácteo sino en toda la economía.

La aparición de las presiones inflacionarias motivó la instrumentación de acuerdos de precios tendientes a morigerarlas, convirtiéndose en una de las principales armas en torno de las cuales pivoteó la política antiinflacionaria entre 2005 y 2007. Complementariamente, se apeló a subsidios, retenciones, reducción del IVA y publicación de precios en diversos productos. Motorizados desde la Secretaria de Comercio Interior creada 
en abril de 2006, los acuerdos de precios incluyeron no sólo lácteos sino también otros alimentos (carne, pan, cereales y derivados, frutas y verduras, pollo, pescado) y rubros muy diversos tales como golosinas, útiles escolares, medicina prepaga, colegios privados, automotores, artículos de higiene y tocador y aún indumentaria, sobrepasando los cien acuerdos entre Gobierno y cámaras empresarias o empresas individuales. Algunos economistas sostienen que los acuerdos fueron exitosos en un primer momento, pues la inflación anual medida por el Instituto de Estadística y Censos (INDEC) se redujo desde el 12,3 \% en 2005 al 9,8 \% en 2006 (Montenegro 2011). La suba de precios sin embargo se atenuó sólo en los primeros meses del 2006.

Las medidas de política instrumentadas en el sector lácteo hasta el año 2007 buscaron así atenuar el impacto sobre los consumidores de la suba de precios domésticos que seguían la trayectoria ascendente de los precios internacionales. Ante este diagnóstico, los acuerdos de precios, las retenciones y el control de valores de exportación que se instrumentaron buscaban desacoplar los precios internos de los precios en el mercado internacional.

En cuestiones estrictamente lácteas, el gobierno celebró en marzo del 2005 un compromiso con el Centro de la Industria Lechera para bajar los precios entre un 1,5\% y $8 \%$ (referidos a leche fluida, yogur y queso) y en 2006 se formalizaron nuevos acuerdos con las dos firmas líderes para mantener fijos por un año los precios de un amplio conjunto de productos (leche, manteca, quesos diversos, etc.), instrumentándose asimismo un Programa que incluía baja de retenciones, mantenimiento de los precios domésticos y la creación de un Fondo Compensador para subsidiar productores.

Los derechos de exportación fijados en 2002 se mantuvieron sin modificaciones hasta 2005. En marzo de ese año, el Centro de Industria Lechera decide denunciar el acuerdo de precios en un momento de aumento del consumo interno de lácteos y precios y demanda externa sostenidos. Ante ese hecho, al ser considerada la estabilidad de precios una cuestión central en la política macroeconómica, por Resolución del 22/7/2005 se incrementaron por 180 días los derechos de exportación 15\% o 10\%, dependiendo de la ubicación del producto en la Nomenclatura Común del Mercosur, más altos para la leche en polvo (MEP, Ministerio de Economía y Producción, Res. 406/ 2005). Adicionalmente, en noviembre de 2005 se suspendieron los reintegros a la exportación de lácteos argumentándose que el producto es un bien salario, tratando de "resolver la tensión estructural entre consumo y exportación” (MEP, Res. 616/ 2005). La medida fue prorrogada hasta agosto de 2006 volviéndose luego a los derechos de exportación fijados en 2002. El mismo año, la AFIP, por medio de la Resolución General 1866 implementó a través de la Dirección General de Aduanas el sistema de "valores referenciales de exportaciones de carácter precautorio...", quedando la DGA facultada para establecer altas, bajas y modificaciones. El resultado de las retenciones fue la interrup- 
ción de la dinámica ascendente de los ingresos de la producción del tambo iniciada en 2004 gracias a la mayor demanda mundial, sin que se notara la misma desaceleración en los precios al consumidor, lo que reacomodó las posiciones relativas a favor de la industria (Bisang et al, 2007)

Ante los escasos resultados obtenidos por las medidas instrumentadas, en enero 2007 se intenta superar estas limitaciones mediante un accionar "coordinado y coherente", instrumentándose el "Programa de estabilización de precios de productos del sector lácteo destinados al mercado interno"(MEP, Res. 61/ 2007), medida que constituye la principal intervención del Ministerio de Economía y Producción de carácter general en el mercado lácteo. Las medidas incluyen no sólo retenciones móviles, reintegros y precios de referencia sino también subsidios a los tamberos a distribuir mediante la ONCCA. En los considerandos de la norma se destacan:

- Presiones de demanda en el mercado internacional derivadas de bajas relaciones entre el stock y el consumo con el consiguiente aumento de precios.

- Necesidad y posibilidad de evitar el arbitraje de precios estableciendo mecanismos que aseguren el abastecimiento del mercado interno.

- La importancia de armonizar los intereses de los distintos eslabones de la cadena de valor láctea

- El acuerdo firmado el 4 de enero de 2007 destinado a la creación e implementación de un sistema de compensación de los mercados de productos lácteos para estructurar un conjunto de precios relativos.

- El aporte del sector a las políticas de estabilización de precios.

- Participación de los tamberos en la renta adicional originada en el aumento de los precios internacionales.

- Creación de un programa de estabilización de precios internos.

- Precio de corte para la leche en polvo entera propuesto por el sector privado

- Se agrega al precio de corte un diferencial de costo para las leches en polvo estuchadas, enlatadas y descremadas atendiendo al mayor valor agregado que implica su industrialización

- La conveniencia de establecer un único derecho de exportación para todos los productos del sector lácteo.

- Necesidad de fijar un derecho de exportación adicional y transitorio para las leches en polvo tomando como base el precio de corte.

La Resolución establece que:

- Los tamberos, para ser beneficiarios del programa, deben estar registrados ante la ONCCA, debiéndose también mantener los precios internos acordados entre industria y gobierno. 
- Los beneficiarios reciben un aporte no reintegrable por litro de leche bovina fluida sin procesar con destino a la industrialización.

- La Autoridad de Aplicación del Programa será asesorada por un Comité conformado por entidades del sector privado representadas por la Mesa nacional de Productores de Leche, el Centro de la Industria Lechera, la Junta Intercooperativa de Productores de leche y la Asociación de Pequeñas y Medianas Empresas Lácteas junto con funcionarios del Ministerio de Economía y Producción.

- La SAGPyA debe elaborar quincenalmente un precio de referencia en dólares por tonelada de leche en polvo entera y la Dirección General de Aduanas debe establecer valores referenciales de exportación de carácter precautorio con los alcances de la Resolución General 1866 de Abril de 2005 de la AFIP.

- El precio de corte de la tonelada de leche en polvo entera es el propuesto por el sector privado: u $\$$ s 2.100 .

- El Derecho de exportación adicional para leche y crema concentradas o con adición de azúcar en polvo, gránulos o demás formas sólidas resulta de:

$\cdot \mathrm{d}=\left\{\left[\mathrm{FOB}\left({ }^{\star}\right)-(\mathrm{VC}+\mathrm{VD})\right] /(\mathrm{VC}+\mathrm{VD})\right\} \times 100$ donde:

- d: alícuota adicional del derecho de exportación

- FOB ( $\left.{ }^{\star}\right)$ : precio FOB de exportación menos el Derecho de Exportación (D.E.) fijado en la Resolución 672/06 MEP (reemplazado por anexo I)

- VC: valor de corte

- VD:Valor diferencial de costo para envases de hasta $2 \mathrm{~kg}$ y mayor para enlatados.

- Si el FOB(*) es menor a (VC+VD) la alícuota adicional es cero.

- Se exceptúa del pago del derecho adicional a las mercaderías que se exporten para cancelar préstamos de largo plazo concertado con agencias gubernamentales extranjeras.

Al admitir los "precios de corte", los industriales buscaban de este modo evitar una eventual prohibición de las exportaciones y el Estado por su parte captaba la diferencia entre el precio internacional y el precio de corte.

Pocos días después de la implementación del programa de estabilización de precios, la AFIP comienza a publicar valores referenciales de exportación para mercaderías y grupos de países de destino. Los valores de referencia buscaban por su parte controlar el problema de la subfacturación.

En función de lo expresado en la Resolución 61, en junio se modifican asimismo los derechos de exportación de lácteos, lo que vuelve a hacerse en diciembre de 2008. En ambos casos también se modifican los valores de referencia y los valores diferenciales de costo. 
Adicionalmente, en septiembre se faculta a la ONCCA para registrar los compromisos de compraventa al exterior y de todas las operaciones de exportación e importación de lácteos, con lo que se crea el ROE BLANCO, por medio del cual se debe solicitar la autorización antes de realizar operaciones de exportación de lácteos. Entre los requisitos que se imponen para autorizar exportaciones figura que las usinas lácteas en su conjunto deben mantener un stock mínimo de 25.000 toneladas de leche en polvo. Además se indican 14 causas de rechazo de los ROE BLANCO, las cuales no son taxativas y pueden incrementarse o modificarse en función de los controles que se realicen.

\section{Las Politicas hacia los tamberos}

El Ministerio de Economía y Producción creó en abril 2006 el "Programa de apoyo al sector tambero", en virtud del cual se asignan inicialmente $\$ 9.000 .000$ provenientes de la recaudación de los derechos de exportación (Resolución 255/2006). El 85\% del monto se destina a subsidiar tasas de interés para inversión o capital de trabajo con plazos de hasta 5 y 1 años respectivamente, con una participación provincial de 23,50\% para Buenos Aires, 33,30\% para Córdoba, 33,60\% para Santa Fe, 7,60\% para Entre Ríos y $2 \%$ para La Pampa. El otro $15 \%$ se destinaba a capacitación de productores tamberos $(0,60 \%)$, plan piloto para la creación de un mecanismo de pago basado en un sistema nacional de determinación de calidad de leche $(11,10 \%)$, introducción de la actividad en zonas no tradicionales $(2,20 \%)$ y estudios interdisciplinarios de la cadena láctea $(1,10 \%)$. Al quedar los costos de producción por encima de los precios percibidos por los productores, los subsidios intentaban neutralizar el efecto negativo. La baja de la producción, un $6 \%$ en el 2007, y los aumentos de costos ocurridos durante 2006 fueron los detonantes de estas medidas.

En el 2007 se instrumentaron a su vez subsidios al consumo interno con el fin de facilitar el abastecimiento de alimentos al grueso de la población a precios accesibles; primero se focalizaron sobre los industriales que vendieran en el mercado interno productos derivados del trigo, maíz, girasol y soja (MEP, Res. 9/ 2007), extendiéndoles luego a la producción lechera (ONCCA, Res.40/ 2007). El subsidio se estableció en \$0,05 por litro y lo percibían los industriales que debían trasladarlos a los tamberos (ONCCA, Res.745/2007), siempre y cuando se mantuvieran los precios de salida de fábrica de los productos subsidiados a los niveles de noviembre de 2006.

Condiciones climáticas adversas en 2007 disminuyeron drásticamente las reservas de forraje y la caída en los rendimientos de los tambos redujo sensiblemente la producción. Como consecuencia, en diciembre se firmó un acuerdo marco entre los sectores público y privado para incentivar la producción primaria. Se instrumentaron así nuevos aportes no reintegrables a los tamberos inscriptos en la ONCCA y que hubieran recibido el subsidio de la Resolución 745/07. Los aportes se pagaban en tres cuotas en febrero, marzo y abril. Los montos a percibir son de acuerdo a la Resolución 48/2008 
del MEP: $\$ 0,07$ por litro a los productores que no superen los 5.000 litros diarios, $\$ 0,07$ por litros por los primeros 5.000 litros y $\$ 0,03$ por litro los litros siguientes a los productores de hasta 10.000 litros diarios y a los que exceden esa producción $\$ 0,05$ por litro los primeros $5.000, \$ 0,07$ los siguientes 5.000 y $\$ 0,01$ por litro los restantes.

A principios de julio de 2008 se firma un nuevo acuerdo marco y vuelven a otorgarse aportes no reintegrables a los productores tamberos, pero esta vez de $\$ 0,102$ por litro hasta alcanzar 6.000 litros de promedio diario durante junio, julio y agosto, calculado para cada mes en forma individual (MEP, Res. 169, 2008). En el mecanismo operativo para el pago, se especifica que sería beneficiarios hasta 6.000 litros los productores que no superaran los 12.000 litros diarios. Por encima de ese límite no percibirían el aporte. En septiembre se prorrogó por un mes el acuerdo de precios y por lo tanto se hizo lo mismo con el aporte.

Durante 2009 se mantuvo el sistema de acuerdos de precios y aportes a los productores, aunque con cambios frecuentes. En marzo se aprobaron aportes para los tamberos con una producción promedio de hasta 3.000 litros diarios entre junio y septiembre de 2008. El aporte se fijó en $\$ 0,10$ multiplicado por el promedio mensual de leche, no pudiendo superar un pago equivalente a 3.000 litros diarios y se distribuiría en 10 meses desde marzo hasta diciembre (SAGPyA, Res. 169, 2009). Posteriormente se decide incorporar a los tambos que hayan producido hasta 6.000 litros para los productores asociados a las entidades que firmaron el acuerdo con el gobierno en junio (SAGPyA, Res. 393, 2009). Finalmente, se amplió el mecanismo para abarcar a los productores de hasta 12.000 litros asociados a entidades firmantes del acuerdo de julio, mientras que el resto podría adherir por 30 días corridos. El pago se pautó para cinco meses, de agosto a diciembre de 2009 y por un monto de $\$ 0,20$ multiplicado por el promedio mensual de producción, sin que pueda superar un pago equivalente a 3.000 litro por día(SAGyP, Res. 513/ 2009).

\section{Apoyo a la industria láctea}

La Resolución 435/07 del Ministerio de Economía y Producción establece el mecanismo para el cálculo de la compensación de precios a los industriales lácteos, previsto en el artículo $2^{\circ}$ de la Resolución 40/07. Considera que el precio del litro de leche cruda compatible con los de salida de fábrica pautados con el gobierno nacional es de $\$ 0,51$ y por lo tanto compensa la diferencia entre ese valor y el precio pagado entre el 1/2/07 y el 30/4/07.

En septiembre de 2007 se prorrogó hasta el 30 de junio y se actualizó la compensación considerando el precio abonado por litro de leche cruda o $\$ 0,70$, el que resultara menor. En diciembre se incorporó el período desde el 1/7/07 y el 31/10/07 y se actualizó el costo de la compensación a \$0,55 por litro. Finalmente se incorporó el lapso entre el 1/11/07 y el 31/1/08, manteniendo los montos para el cálculo de la compensación. 


\section{El Programa Nacional de Lechería}

En 2010 se retomó la senda de la Resolución 320 de 2002 y se asignaron \$48 millones al Programa Nacional de Lechería (MAGyP, Resolución 297, 2010).

Los objetivos principales que se plantea el programa son los mismos que venían guiando el accionar hasta ese momento: participación activa del Estado, garantizar la soberanía y seguridad alimentaria nacional, incorporar mayor valor agregado a la producción y promover el cooperativismo y asociativismo.

Entre los objetivos específicos se mencionan: defensa de pequeños y medianos productores, garantizar el abastecimiento del consumo interno, crecimiento sostenido de la producción con medidas que eviten los ciclos de sobre y sub oferta, redacción del proyecto de ley de lechería consensuado con los actores de la cadena, incremento de la productividad, ley de arrendamiento, diferenciación impositiva por actividad, derecho de exportación por actividad y transparencia de la cadena (pago de leche por atributos de calidad, leche promedio nacional comparativa, red de laboratorios lácteos, precio de referencia, liquidación única, certificados de depósito de leche, costos de producción, precio promedio pagado).

Los beneficiarios pueden ser fundaciones que tengan entre sus objetivos la actividad láctea, escuelas agrotécnicas, cámaras sectoriales de la producción y la industria, provincias y municipios, asociaciones civiles, cooperativas, productores tamberos inscriptos en el RENSPA Registro Nacional Sanitario de Productores Agropecuarios) y en los registros provinciales y pequeñas y medianas industrias lácteas inscriptas en la ONCCA. En octubre 2010 se creó el Consejo Federal Lechero (MAGyP, Res. 412/ 2010) conformado por un titular y un suplente por parte del Ministerio de Agricultura, Ganadería y pesca y de los gobiernos de las provincias de Santiago del Estero, La Pampa, Entre Ríos, Santa Fe, Córdoba y Buenos Aires. Sus funciones son: generar propuestas con carácter de recomendación, proponer normativas, debatir los temas relacionados con el sector en función de la política lechera nacional, conformar un sistema de información permanente, proponer políticas para el desarrollo sostenible de los pequeños productores y el fomento del asociativismo, formular propuestas de promoción del consumo y coordinar programas de capacitación.

Finalmente, en 2011 se puso en marcha un viejo anhelo del sector productivo: el sistema de pago de leche cruda sobre la base de atributos de calidad composicional e higiénicosanitarios en sistema de liquidación única, mensual, obligatoria y universal(MAGyP y MEyFP, Res. 739 y Res. 495, 2011), el cual debería entrar en plena vigencia y cumplirse todas las obligaciones dispuestas a partir del 1/4/11; asimismo se creó un nuevo Registro de Productores Tamberos(SAGyP, Res.683/ 2011). ${ }^{8}$ 


\section{Resultados y Desempeño}

La evolución del sector lácteo argentino puede ser analizada atendiendo los objetivos que guiaron el accionar y las medidas de política instrumentadas en el lapso bajo estudio. Los motivos que guiaron el accionar en definitiva pueden ser resumidos en:

- Desacoplar la evolución de los precios internos de los internacionales

- Aumentar la producción de leche cruda

- Aumentar el consumo interno

- Aumentar la exportación

- Mejorar la situación de los productores tamberos

La suba de los precios internacionales no se reflejó plenamente en los precios percibidos por los productores en el lapso comprendido entre 2003 y 2008 (Gráfico 1), aunque acompañó la tendencia creciente que se reflejó en el indice internacional de precios de productos lácteos de la FAO y en el precio de la leche en polvo entera de Oceanía (LPE). Ante este panorama el gobierno nacional reaccionó interviniendo en 2005 mediante el aumento de la alícuota de los derechos de exportación del $5 \%$ al $10 \%$ o al $15 \%$ según el producto, más elevada para la leche en polvo. Pero con posterioridad, los precios de la leche en tambo recuperaron el terreno perdido y crecieron a mayor velocidad que los precios internacionales. ${ }^{9}$ La producción de leche, que enfrentaba serias dificultades climáticas y había caído un $6 \%$ en 2007, se recuperaría en los años posteriores. Primero levemente, creciendo significativamente recién en el año 2011, casi un $9 \%$.

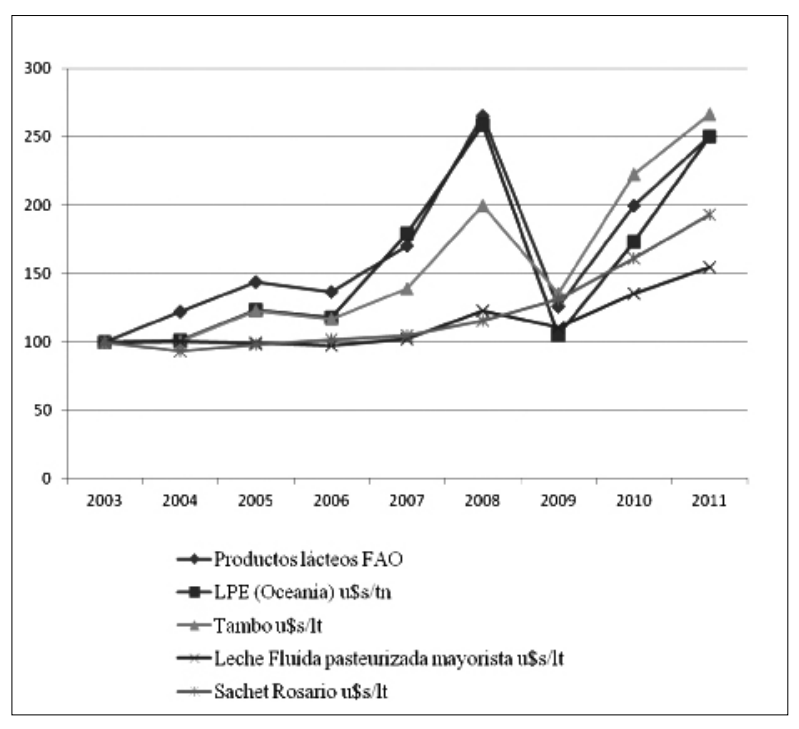

GRÁFICO 1

Índices de Precios

base marzo $2003=100$
Fuente: elaboración propia con datos de FAO, Diary Market News (USDA), INDEC, BCRA, Márgenes Agropecuarios, IPC Rosario y AACREA 
Los precios de la leche al consumidor según el Índice de Precios de Rosario y aquellos a nivel mayorista que releva el INDEC evolucionaron de manera similar hasta el año 2008, sin acusar tampoco aumentos de magnitud. Sin embargo, con posterioridad la leche al consumidor se distanció significativamente del precio de la leche a nivel mayorista. De todas formas en ambos casos, si bien la evolución de los precios ha sido creciente en el período analizado, el aumento ha sido menor que en el caso de los precios internacionales y en tambo.

La producción primaria tuvo una recuperación muy importante a partir del año 2003 creciendo al 4,4 \% anual acumulativo. En términos históricos, sin embargo, esta tasa es sensiblemente inferior a la observada en el ciclo expansivo anterior, 1991/1999, que redondeó un valor del 7,2 \% anual. El record de producción del ciclo anterior, 10.329 millones de litros en 1999, fue superado recién en 2011, año en que se produjeron 11.206 millones de litros (Gráfico 2).

\section{GRÁFICO 2}

\section{Evolución de la producción de leche entrada a fábrica (millones de litros)}

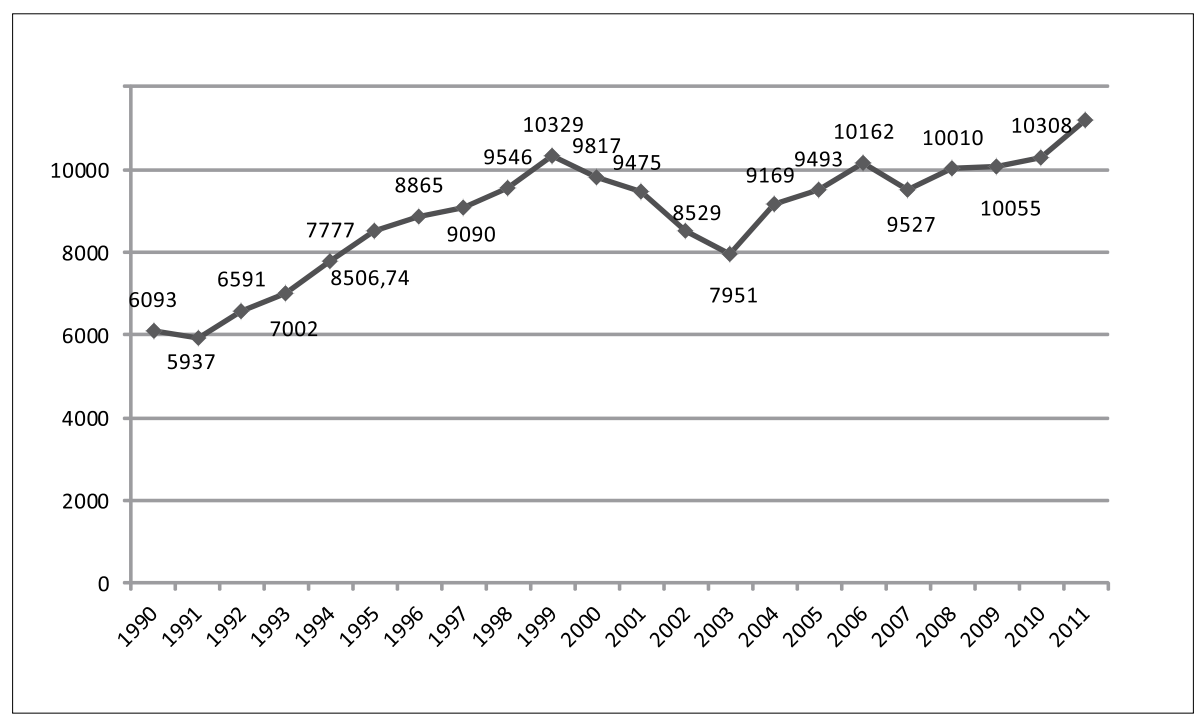

Fuente: Lácteos - Dirección de la Industria.

El consumo de lácteos tuvo también una importante recuperación a partir de la reactivación, acorde con la habitual correlación positiva que se detecta entre ingreso por habitante y consumo de leche. ${ }^{10}$ Partiendo del menor valor de la serie observado en el año 2003, 0,49 litros por habitante por día, se expandió en forma persistente hasta alcanzar los 0,56 litros por habitante por día en 2009, valores que se mantuvieron en los dos años posteriores. En términos históricos sin embargo estos registros son aun inferiores a los detectados quince años atrás: 0,58-0.63 litros por habitante por día en el lapso 1992-2001 (Gráfico 3). 


\section{GRÁFICO 3. Consumo per cápita de lácteos (litros por día)}

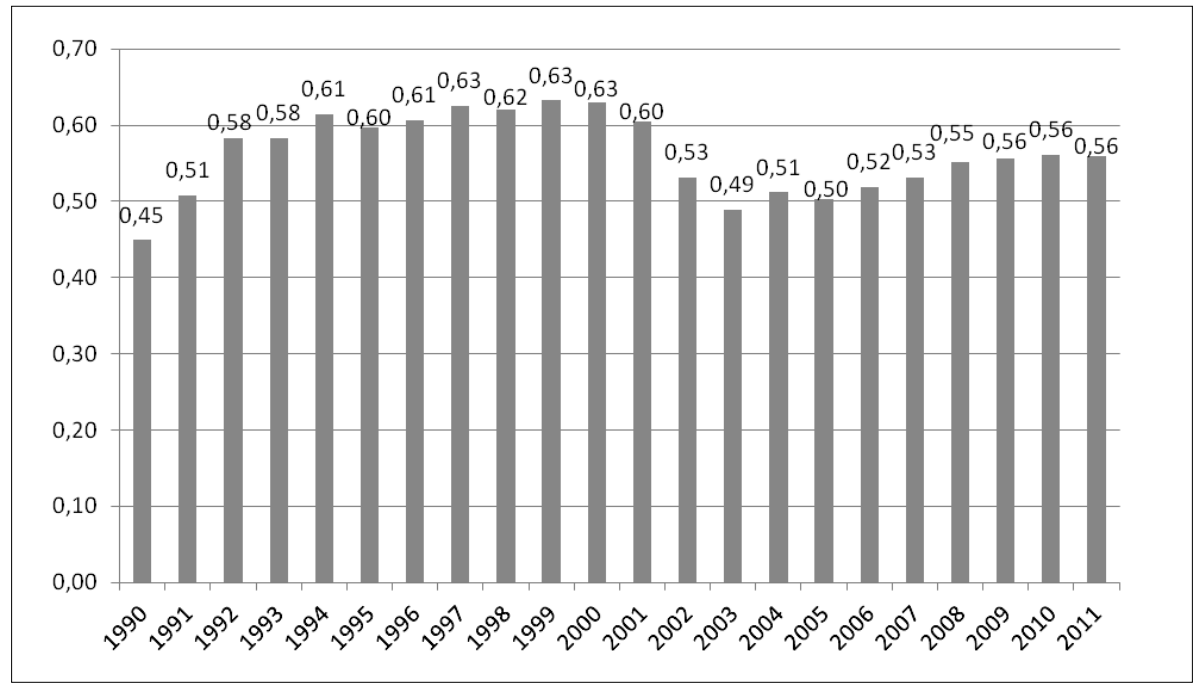

Fuente: Ministerio de Agricultura, Ganadería y Pesca. Susecretaría de Lechería.

Las exportaciones lácteas por su parte exhibieron niveles muy elevados. Aunque con altibajos, los valores observados estuvieron muy por arriba de los reducidos valores exportados en 2001, que medidos en millones de litros equivalentes fueron de 1163. Crecieron en forma ininterrumpida año a año alcanzando los 2850 millones de litros equivalentes en 2006. Se mantuvieron en torno de los 2000 millones de litros con posterioridad aunque en 2011 sobrepasaron los 2700 millones. (Gráfico 4).

\section{GRÁFICO 4. Exportación de leche (millones de litros)}

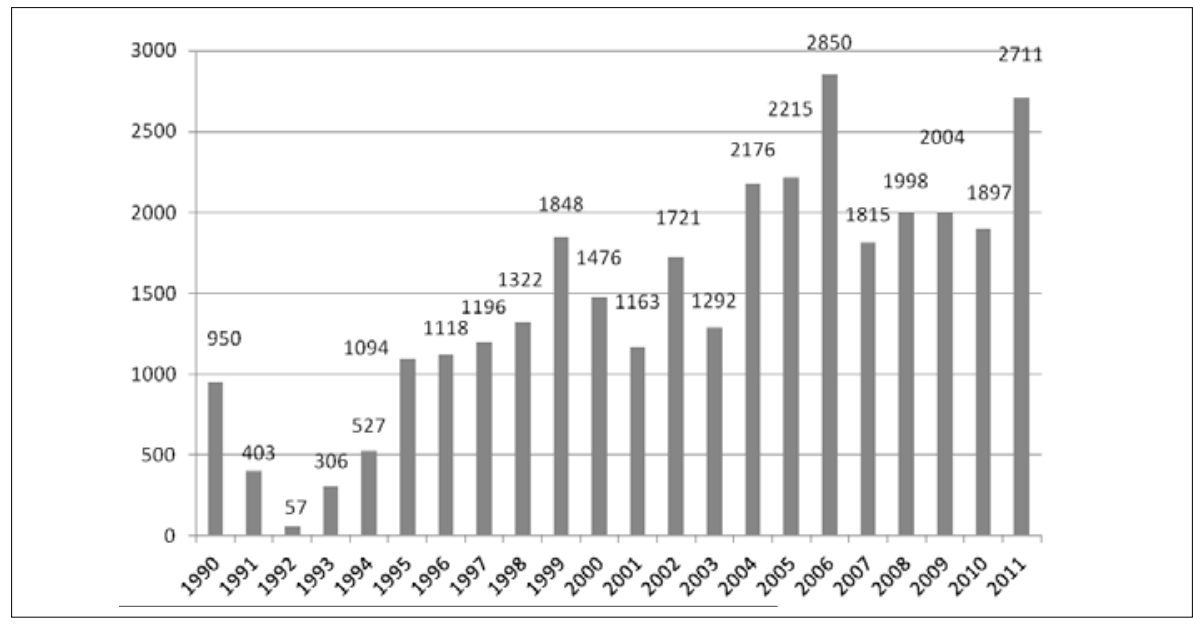

Fuente: Ministerio de Agricultura, Ganadería y Pesca. Susecretaría de Lechería. 
La importancia de las exportaciones lácteas con relación a la producción doméstica ha alcanzado así valores históricamente elevados. Los 2700 millones de litros equivalentes exportados representaron la cuarta parte de la producción nacional de leche. ${ }^{11}$ Un nivel algo menor al registrado en el año 2006 (28 \%) aunque ahora se logra con un volumen de producción significativamente mayor, 11.206 millones de litros versus 10.162 millones, lo que permitió mantener los niveles de consumo en valores relativamente elevados, 0,56 litros por habitante por día versus 0,52 litros por habitante por día en 2006.

El sector lácteo por su parte ha pasado a ser también un proveedor de divisas de relevancia. Si en 1991 exportó sólo 65 millones de dólares y diez años después lo hizo por algo menos de 300 millones, en 2011 estos valores habían aumentado un $500 \%$, fruto de excelentes precios internacionales pero también por efecto de aumento en las cantidades. Las toneladas de productos lácteos exportadas en 2011 en efecto fueron tres veces las exportadas en 2001. Redondearon unas 450 mil y aportaron 1595 millones de dólares (Gráfico 5). La leche en polvo por su parte perdió algo de protagonismo ya que representó el $52 \%$ de total exportado, bastante por debajo del 73 \% que aportó en 2001. Leches especiales, manteca, sueros y caseína ganaron a su vez algo de participación.

\section{GRÁfICO 5. Exportaciones de Productos Lácteos}

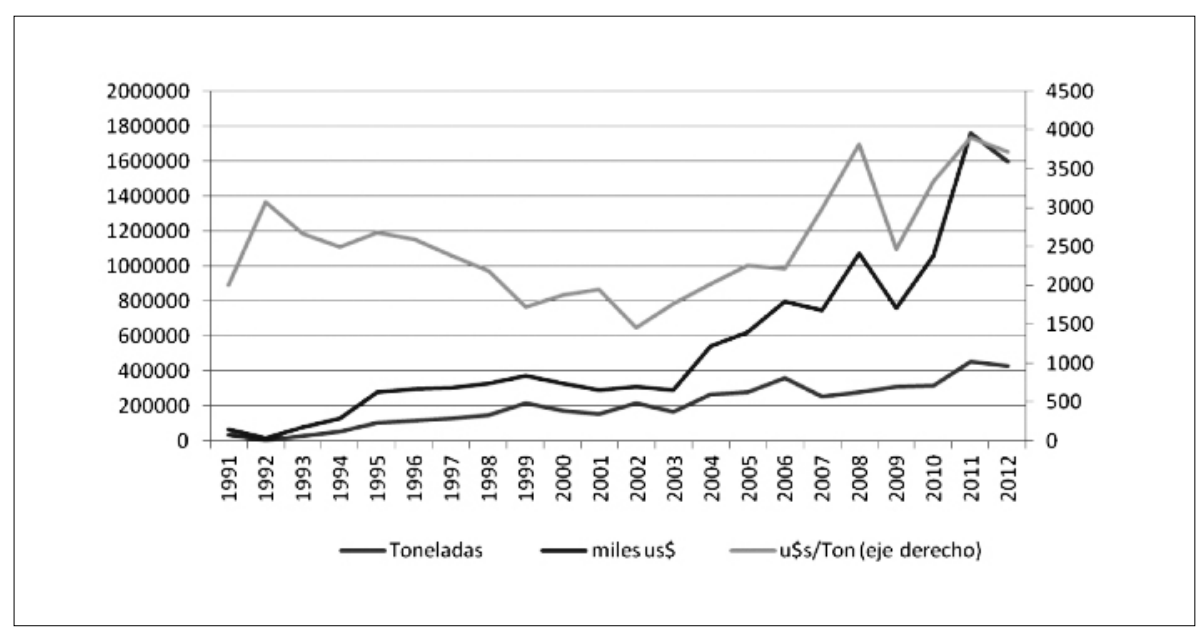

Fuente: Ministerio de Agricultura, Ganadería y Pesca. Susecretaría de Lechería.

La rentabilidad de la actividad a nivel del productor pareciera no haber experimentado mejoras de magnitud. En los primeros años sin embargo los precios al productor se mantuvieron en niveles relativamente elevados impulsados por la recuperación económica y los mayores niveles de consumo. Esto habría frenado en un primer momento el éxodo de productores y el cierre de tambos, deteniéndose a su vez la faena de vientres (Quintana y Reca, 2009). Con posterioridad sin embargo los precios recibidos por los tamberos se 
retrasaron notablemente respecto de los costos de las explotaciones medidos en $\mathrm{u} \$ \mathrm{~s}$ por ha, impulsados por la suba de los precios internacionales de todos los commodities y de los insumos (Gráfico 6). El clima jugó asimismo en forma adversa: en el otoño de 2007 las inundaciones provocaron severos daños en la principal cuenca lechera del país, en tanto que en 2008 faltó también el agua y en el 2009 se registró en las cuencas lecheras más importantes una sequía sin antecedentes en los últimos setenta años.

\section{GRÁFICO 6. Precio al productor y costo del tambo (base $2003=100$ )}

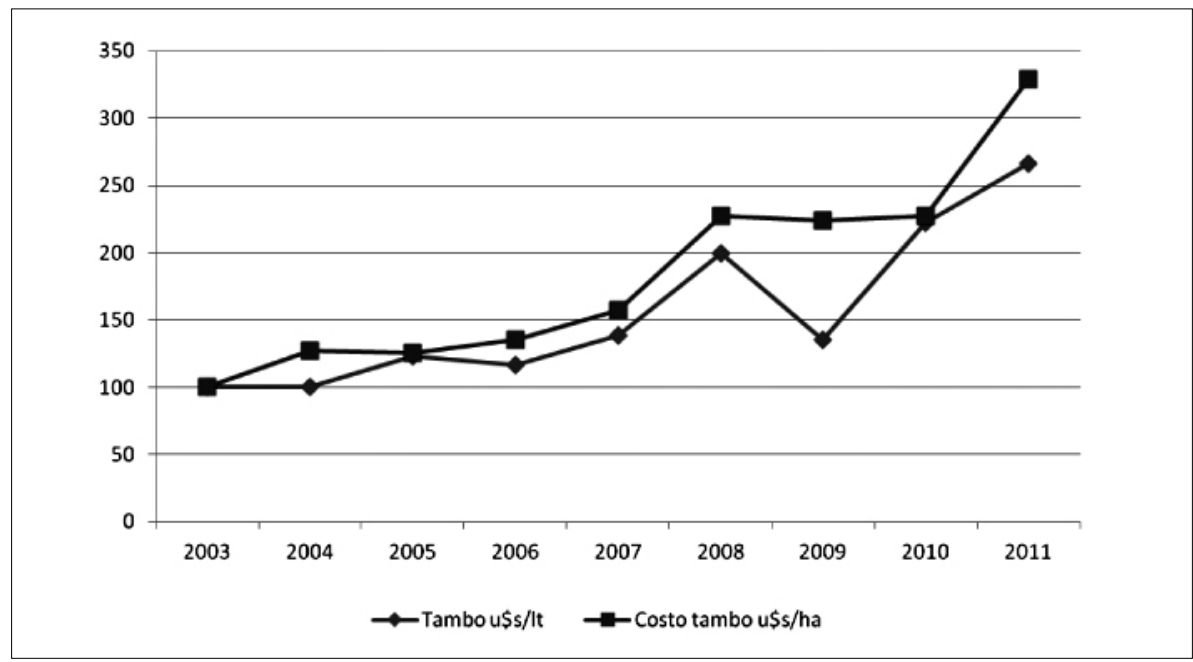

Fuente:AACREA y Márgenes Agropecuarios

El precio percibido por el productor no cubrió en muchos casos los costos de producción, situación que impulsó a las autoridades a intervenir mediante el otorgamiento de subsidios y aportes a los tamberos, ante la dificultad práctica de actualizar permanentemente el precio de corte de las exportaciones. La suspensión de los aportes a partir del año 2010 agravó los problemas de rentabilidad de los años posteriores, más aún cuando se recuerda que el pago de esos aportes no tuvo en muchos casos la regularidad necesaria. Se difundieron casos de atrasos significativos en las percepciones y también de falta de pagos en su totalidad por razones diversas, que incluían un amplio abanico de circunstancias: desde falta de cumplimiento de los productores de todos los pasos administrativos hasta denuncias publicitadas de falta de transparencia en el organismo encargado de los pagos. Hubo períodos incluso en que la industria dejó de recolectar leche en algunos tambos y en otros casos pagó precios diferenciales para mercado interno y exportación. Alargamiento de plazos de pago y sobrestocks por dificultades para la exportación tuvieron también en algunos casos estado público. Ante las dificultades de abastecimiento, algunas industrias instituyeron en 2010 premios por aumento de producción. 
La evolución de los precios en las diferentes etapas de la cadena desde el tambo hasta la góndola del supermercado exhibe disparidades y demanda la necesidad de buscar articulaciones entre los diferentes sectores de un producto básico para la dieta alimentaria que muestra en todo el mundo fuertes regulaciones. En este contexto, resulta oportuno mencionar el desafio planteado desde la Facultad de Agronomía de la Universidad de Buenos Aires, destacando las posibilidades que podría aportar el abordaje de la problemática del sector lácteo argentino desde el Enfoque de la Nueva Economía Institucional, ante las asimetrías que exhiben los senderos de los precios al productor, de los eslabones intermedios y los precios en la góndola. Dicho trabajo, en efecto, demanda “...mejoras en la calidad del ambiente institucional con políticas que permitan la construcción de ventajas competitivas sostenibles, [...ya que mientras...] no se rediseñen contratos formales que reduzcan la incertidumbre y no respeten los acuerdos entre las partes, será muy difícil mejorar el escenario del sector lácteo bovino en la Argentina”. (PPA, 2009)

\section{Conclusiones}

El sector lácteo argentino ha tenido una importante recuperación en la primera década del nuevo siglo en materia de producción. No obstante, fue recién en 2011 que la producción obtenida, 11.206 millones de litros, superó el record del ciclo expansivo anterior que finalizó en 1999. Transcurrió demasiado tiempo para recuperar la memoria "productiva".

El principal punto a destacar sin embargo es la extraordinaria expansión de los valores exportados, fruto de excelentes precios internacionales pero consecuencia también de aumentos muy importantes de las toneladas exportadas. El sector lácteo ya no es tan marginal y genera un importante volumen de divisas a la economía nacional. En 2011 se exportaron 450 mil toneladas de productos por casi 1800 millones de dólares, un $200 \%$ y un $500 \%$ más elevados respectivamente que los registros de diez años atrás. A diferencia de lo ocurrido en 2006, sin embargo, este importante nivel de exportaciones se obtuvo en un contexto de mayor producción que permitió no resentir el consumo doméstico.

La recuperación del consumo por habitante es en efecto otro elemento que debe ser enfatizado. Los valores registrados sin embargo continúan siendo inferiores a los registrados veinte años atrás. Esto coloca en el centro de la discusión las dificultades para articular un creciente aumento de la ingesta láctea de la población y una expansión simultanea de las exportaciones del sector, buscando captar en su plenitud las rentas derivadas de una coyuntura internacional muy favorable en materia de precios. La tradicional tensión entre mercado interno y mercado internacional en expansión no ha podido ser superada aunque habrían aparecido algunos avances en ese sentido. Las políticas 
de intervención, obsesionadas por controlar los precios a nivel de la góndola un lustro atrás, parecieran haberse diversificado incorporando otras herramientas vinculadas a cuestiones tecnológicas y de calidad. En este sentido, merecen destacarse las expectativas favorables que genera el nuevo sistema de pagos al productor en base a atributos de calidad, una antigua aspiración sectorial destinada a generar mejores incentivos y premios a las buenas prácticas de manejo. 
${ }^{1}$ Capellini (2011) ha destacado por ejemplo las importantes ventajas comparativas y competitivas pero también"..significativas barreras internas y externas para la expansión de la industria láctea".

${ }^{2}$ Sin embargo Lema y Gallacher (2004) consideran a la industria procesadora de leche como relativamente competitiva debido a la ausencia de barreras de entrada, con un valor cercano a 0,06 para el índice de Herfindahl y Hirschman

${ }^{3}$ Estos datos están sujetos a elevada controversia. El Censo de 2002 computó unos 20000 tambos ; Quintana y Reca (2010) estiman en la actualidad que existen unos 15000 productores y a fines de la década de los 80 los cifraban en 32400 productores, mientras que el Centro de Industria Lechera considera 11.500 tambos en la actualidad. Gorenstein et al (1988) hablan de unos 55000 productores a mediados de los 80 que tienen en producción unas 2.700 .000 vacas holando-argentino.

${ }^{4}$ En 1996 se libera el uso comercial de la soja transgénica lo que, junto con la difusión de la siembra directa y el uso del glifosato, genera una fuerte competencia por el uso de la tierra debido a la mayor rentabilidad y menor período de producción de la soja (Bisang et allí, 2008)

${ }^{5}$ Las cuencas lecheras principales son: Mar y Sierras, Oeste, Abasto Norte y Abasto Sur en la provincia de Buenos Aires; Sur y Central en Santa Fe; Sur, Villa María y Noreste en Córdoba; Ay B en Entre Ríos y La Pampa en la provincia homónima.

${ }^{6}$ Conformada a partir de las mesas de política lechera provinciales de la producción, industria y gobierno de Santa Fe, Córdoba, Buenos Aires, Entre Ríos y La Pampa y la participación de la SAGPyA.

${ }^{7}$ Integrado por representantes de los gobiernos provinciales y la SAGPyA

${ }^{8}$ Por Resolución 344/13 del Ministerio de Agricultura, Ganadería y Pesca, a partir del 01/09/2013 entró en vigencia la obligación de pagar en un $95 \%$ por la calidad composicional higiénico sanitaria y únicamente un $5 \%$ por beneficios comerciales. Al momento de escribirse este trabajo, el Centro de Industria Lechera había presentado una medida cautelar para suspender la aplicación de la norma

${ }^{9}$ Tendencias similares exhibió el sistema de pago de leche de referencia de Santa Fe que elabora el gobierno provincial. Deflactado por los precios mayoristas, los precios al productor a medidos de $2011(\$ 1,50-\$ 1,60)$ estaban muy por encima de aquellos registrados en la crisis de 2009 ( $\$ 1$ ) y en Enero 2007 (\$0,8); en enero de 2002, menor valor de la serie, se registró \$0,62.

${ }^{10} \mathrm{El}$ consumo de lácteos entre países se muestra a su vez fuertemente correlacionado con el ingreso per capita, el crecimiento poblacional y los cambios de hábitos alimentarios derivados del desarrollo económico y el proceso de urbanización

${ }^{11}$ De acuerdo a las estimaciones oficiales del Ministerio de Agricultura, las exportaciones lácteas medidas en litros de leche equivalente representaban: $7 \%$ en 1991, $13 \%$ en 1995, $18 \%$ en 1999, $20 \%$ en 2002, $23 \%$ en $2005,19 \%$ en 2007 y $24 \%$ en 2011. 


\section{Referencias Bibliográficas}

Bisang, R., Porta, F., Cesa, V., \& Campi, M. (2008) Evolución reciente de la actividad láctea: el desafío de la integración productiva. Recuperado el 18 de febrero de 2011, de http://www.lacteos2020.org.ar/images/biblioteca/ESTUDIO CEPAL III.pdf

Bisang, R., Porta, F., Cesa, V., Campi, M., \& Fernández Bugna, C. (2007). La cuestión distributiva en la trama láctea argentina: Un análisis a partir de la evolución de los precios $y$ del excedente (estimado) de explotación. Recuperado el 18 de febrero de 2011, de www. http://lacteos2020.org.ar/images/biblioteca/ESTUDIO CEPAL I.pdf

Bisang, R., porta, F., Cesa, V., Campi, M., \& Fernandez Bugna, C. (abril de 2008). La cuestión distributiva en la trama láctea argentina: una aproximación al reparto del excedente de explotación. Recuperado el 19 de febrero de 2011, de http://www.lacteos2020. org.ar/images/biblioteca/ESTUDIO CEPAL I.pdf

Cadena Láctea Argentina (2008). Plan Estratégico para la Cadena Láctea Argentina 2008-2020. Informe de avance julio 2008. Recuperado el 15 de noviembre de 2010, de Cadena Láctea Argentina 2020: http://lacteos2020.org.ar/docs/Documento\%20 PEL\%20Final.pdf.

Capellini, O. R. (2011). Dairy Development in Argentina,. Roma: FAO.

Gorenstein, S., Gutierrez, R., Peri, G., \& Romanelli, R. (1988). Agribusiness in Argentina. The Argentine Agricultural Economy. An analysis on its evolution and present situation. Buenos Aires: Asociación Argentina de Economía Agraria.

Lema, D., \& Gallacher, M. (s.f.) Análisis de la industria láctea: competitividad y relaciones con la cadena. Recuperado el 25 de Agosto de 2011, de http://lacteos2020.org.ar/images/biblioteca/Analisis\%20cadena\%20LEMA.pdf

MAGyP, Ministerio de Agricultura, Ganadería y Pesaca (2010) Resolución 297. MAGyP (2010) Resolución 412. MAGyP (2010) Resolución 505.

MAGyP (2011) Plan Estatégico Agroalimentario y agroindustrial Participativo y Federal 2010-2016. Buenos Aires.

MAGyP y MEyFP, Ministerio de Economía y Finanzas Públicas (2011) Resolución 739 y Resolución 495. 
MEI, Ministerio de Economía e Industria (2002) Resolución 11.

MEP, Ministerio de Economía y Producción (2005) Resolución 406.

MEP (2005) Resolución 616.

MEP (2006) Resolución 255.

MEP (2007) Resolución 61.

MEP (2007) Resolución 9.

MEP (2008) Resolución 169.

MEP (2008) Resolución 48.

MEP (2008) Resolución 576.

Montenegro, M. (2011). Es la EKonomía, estúpido. Buenos Aires: Editorial Planeta.

Nogueira, M. E. (2011) Estado y Sector Lácteo. Historia reciente de la construcción de políticas públicas: Argentina 1983-2008. Rosario: Prohistoria ediciones.

ONCCA, Oficina Nacional de Control Comercial Agropecuario (2007) Resolución 40.

ONCCA (2007) Resolución 745.

ONCCA (2008) Resolución 2457.

ONCCA (2008) Resolución 7527.

ONCCA (2009) Resolución 2241.

ONCCA (2009) Resolución 4.

ONCCA (2009) Resolución 486.

ONCCA (2009) Resolución 5295.

ONCCA (2009) Resolución 6686.

ONCCA (2009) Resolución 6688.

Programa de Agronegocios y Alimentos (PPA) (2009). Crisis de la Leche Argentina. Pérdida de competitividad y falta de transparencia, dos indicadores de la crisis de la leche argentina. Newsletter PPA, Facultad de Agronomia, Universidad de Buenos Aires, 16 de agosto, Recuperado el 14 de marzo de 2012.

Programa de Inserción Agrícola (2010). Oportunidades de acceso via negociaciones internacionales. Caso específico para productos lácteos. Trabajo realizado por J. J. Linari con apoyo, ATN/ME-9565-RG BID-FOMIN, Informe Final, 21 de mayo

Quintana, J., \& Reca, A. (2010) "Lechería. Concretando el potencial existente". En L. Reca, D. Lema, \& C. Flood, El crecimiento de la agricultura argentina. Buenos Aires: Universidad de Buenos Aires; 67-81. 
SAGyP, Seccretaría de Agricultura, Ganadería y Pesca (2009) Resolución 513. SAGyP (2011) Resolución 683.

SAGPyA, Secretaría de Agricultura, Ganadería, Pesca y Alimentación (2002) Resolución 320.

SAGPyA (2006) Resoloución 908.

SAGPyA (2009) Resolución 169.

SAGPyA (2009) Resolución 393.

SAGPyA y ONCCA. (2007) Resolución 39 y Resolución 9.

Secretaría de la Competencia la Desregulación y la Defensa del Consumidor (2002) Resolución 2. 